\title{
Mind body and society
}

\section{Editorial}

Medicine as a discipline is largely focused at curing diseases at individual level which is very important; but the discipline seems oblivious to social causes of illness that put individuals at risk of risks. Professor Sujatha has rightly stated in her book that, "Through tranquilizers, painkillers and counselling; doctors make patients accommodate and adjust to social problems like unemployment, domestic violence and abuse. ${ }^{1}$ Biomedicine has led to increased medicalisation of life where consumption of medicines for slightest discomfort has become a norm rather than exception. ${ }^{2}$ Biomedicine further compartmentalize the human body into different specializations and super-specializations where it views human mind and psyche as a separate discipline, different from other organ systems of body. On the other hand, some Indigenous systems of medicine in India like Ayurveda, Unani, Siddha and Sowa-Rigpa recognizes the interdependence of body and mind and thus adopt a multi-model treatment approach including diet and lifestyle changes along with medicines and medical procedures. ${ }^{3}$ The human body is much more than an anatomical structure and the process of cure has wider psychosocial dimensions. Moreover most of the ailments are resulted due to a lifestyle of drudgery and such a lifestyle is widely supported by major social and political structures. The purpose of propagating a lifestyle of drudgery and then seeking biomedical treatment; is to get sick individuals back to work as soon as possible, for maximum profit generation; where workers just act as pawns in the money-making game, and the profit goes to a few elite hands. ${ }^{4}$

There are social situations that place individuals at "risk of risks". There is a need to address those social adversities which are the root cause of all morbidity; because if our interventions remain restricted to individual level, new individuals will keep on adding to the pool of sick population. We need to modify the influence of those social forces in the community that altered the individual behaviour in the first place. ${ }^{5}$ The poor in every society tend to die first. ${ }^{6}$ Poverty is accompanied by major deprivations in life. Poor are generally unemployed, uneducated and unaware of risky health behaviors to which they are more susceptible as compared to economically welloff individuals. There are other critical determinants of health like discrimination, social inequity, cultural factors and societal norms. Social networks of individuals also determine their health as they lead to either social support or social isolation. Psychosocial environment of individuals have a life-course approach influencing social cohesion and thus health of individuals. ${ }^{7}$

To Conclude; our interventions should also adopt a much wider eco-social perspective and intervene at societal level or policy level. Our research also needs to look at inter-linkages of various societal policies with health. There is a need to discuss policies related to education, employment, working conditions, taxation etc in reference with public health. Other social security policies such as pension
Volume 6 Issue 5 - 2017

\author{
Rohini Ruhil \\ Centre for Social Medicine and Community Health, Jawaharlal \\ Nehru University, India
}

\begin{abstract}
Correspondence: Rohini Ruhil, Centre for Social Medicine and Community Health, Jawaharlal Nehru University, New Delhi, Delhi, India,Tel +91 704227|444, Email drrohiniruhil@gmail.com
\end{abstract}

Received: October 28, 2017| Published: November 27, 2017

policies, insurance policies, food security policies, policies related to women and children etc also have a major influence on health of individuals and there is a need for such debates and discussions in the discipline of public health. The law and order situation in a society along with the state of political stability and economic wellbeing is also a major determinant of health. Thus as a discipline of public health, we can-not remain restricted to preventive medicine; the research work should also discuss other social issues which have much wider implications for public health.

\section{Acknowledgements}

I would like to acknowledge my guide and mentor Professor Rama Baru, Jawaharlal Nehru University, New Delhi, India.

\section{Conflict of interest}

Author declares that there is no conflict of interest.

\section{References}

1. Sujatha V. Sociology of Health and Medicine-New Perspectives. New Delhi: Oxford University Press; 2014. p. 1-338.

2. Rohini R. Some Social Sciences Perspectives in public health. International Journal of Perceptions in Public Health. 2016;1(1):41-49.

3. Sujatha V, Abraham L. Medical Pluralism in Contemporary India. New Delhi: Orient Black Swan Pvt Ltd; 2012. p. 1-387.

4. Doyal L, Pennell I. The Political Economy of Health. London: Pluto Press; 1979. p. 1-360.

5. Rohini R. The Need to Address Social Adversities in Community Health. Indian J Comm Health. 2016;28(3):305-308.

6. Glymour MM, Avendano M, Kawachi I. Social Epidemiology. 2nd ed. New York: Oxford University Press; 2014. p. 1-640.

7. Durkheim E. Suicide: A study in Sociology. Routledge, UK; 1897. p. $1-432$. 